\title{
CHARACTERIZATION OF HIGHER DERIVATIONS ON REFLEXIVE ALGEBRAS
}

\author{
Runling An, Chunhui Xue And Xu Zhang
}

Abstract. Let $\operatorname{Alg} \mathscr{L}$ be a CSL algebra. We say that a family of linear maps $D=\left\{D_{n}, D_{n}\right.$ : $\operatorname{Alg} \mathscr{L} \rightarrow \operatorname{Alg} \mathscr{L}, n \in \mathbb{N}\}$ is higher derivable at $\Omega \in \operatorname{Alg} \mathscr{L}$ if $D_{n}(A B)=\sum_{i+j=n} D_{i}(A) D_{j}(B)$ for any $A, B \in \operatorname{Alg} \mathscr{L}$ with $A B=\Omega$. In this paper, we give a necessary and sufficient condition for a family of linear maps $D=\left\{D_{n}, D_{n}: \operatorname{Alg} \mathscr{L} \rightarrow \operatorname{Alg} \mathscr{L}, n \in \mathbb{N}\right\}$ being higher derivable at $\Omega$ which satisfies one of the following properties: (1) $\Omega=0$; (2) $\Omega$ is a left (or right) separating point of Alg $\mathscr{L}$; (3) $\Omega=P \Omega=\Omega P$ for some nontrivial projection $P \in \mathscr{L}$ and $P \Omega P$ is a left (or right) separating point of $P A \lg \mathscr{L} P$. In particular, if $A \lg \mathscr{L}$ is an irreducible CDCSL algebra or a nest algebra, then $D=\left\{D_{n}, D_{n}: \operatorname{Alg} \mathscr{L} \rightarrow \operatorname{Alg} \mathscr{L}, n \in \mathbb{N}\right\}$ is higher derivable at such $\Omega$ if and only if it is a higher derivation.

Mathematics subject classification (2010): 16W25, 47B49.

Keywords and phrases: Higher derivations, higher derivable maps, CSL algebras.

\section{REFERENCES}

[1] R. AN, J. Hou, Characterizations of derivations on triangular rings: additive maps derivable at idempotents, Lin. Alg. Appl. 431 (2009), pp. 1070-1080.

[2] R. AN, J. Hou, Characterizations of derivations on reflexive algebras, Linear Multilinear Algebra, to appear.

[3] M. BREŠAR, Characterizing homomorphisms, multipliers and derivations in rings with idempotents, Pro. Roy. Soc. Edinburgh Sect. A. 137 (2007), pp. 9-21.

[4] W. S. Cheung, Commuting maps of triangular algebras, J. London. Math. Soc. 63 (2001) 117-127.

[5] F. LU, Lie isomorphisms of reflexive algebras, J. Funct. Anal. 240 (2006), 84-104.

[6] W. XuE, J. Hou, All-derivable points of nest algebras on Banach spaces, Operators and Matrices, 6 (2012), 481-491.

[7] J. ZHU, C. XIONG, All-derivable points in continuous nest algebras, J. Math. Anal. Appl. 340 (2008), $843-853$.

[8] J. ZнаO, J. ZHU, Jordan higher all-derivable points in triangular algebras, Lin. Alg. Appl. 436, 9 (2012), 3072-3086. 